\title{
Additive effect of the root-lesion nematode Pratylenchus penetrans and the fungus Rhizoctonia solani on potato yield and damage
}

\author{
Maria Viketoft ${ }^{1}$ (D) Adam Flöhr ${ }^{2} \cdot$ Jan-Eric Englund $^{2} \cdot$ Jonas Kardell $^{1} \cdot$ Eva Edin $^{3}$
}

Received: 7 October 2019 / Accepted: 11 June 2020 / Published online: 24 June 2020

(c) The Author(s) 2020

\begin{abstract}
The significance of nematodes for disease development caused by other soil-borne pathogens has been demonstrated in many crops throughout the world and specifically prevalent are interactions between plant-parasitic nematodes and species of plant pathogenic fungi. Here, the interaction between the fungus Rhizoctonia solani (AG2) and the migratory endoparasitic root-lesion nematode Pratylenchus penetrans was investigated on potato. The hypotheses were that the combination of $R$. solani and $P$. penetrans would result in more severe canker lesions, reduced quality of the tubers and lower tuber yield, and we also expected higher nematode levels to render more nematode damage. To test this, potato plants were grown in pots in two replicate experiments and the presence and/or abundance of the two pathogens were controlled. The first three hypotheses were rejected as (1) the tuber yield decreased when the fungus and nematode occurred together but not more than the sum of their separate effects, i.e. additive, (2) there was no effect of presence of nematodes on the incidence of stem canker, and (3) the quality of tubers was actually partly improved as the presence of the nematodes reduced the likelihood of elephant hide on the tubers in one of the experiments. As expected, there were more visible nematode damages with addition of more nematodes, but beyond that the different nematode levels rendered in most cases similar responses. To have knowledge about interactions between pathogens, as the one showed here, is essential for disease control through appropriate management methods.
\end{abstract}

Keywords Black scurf $\cdot$ Disease complex $\cdot$ Elephant hide $\cdot$ Solanum tuberosum $\cdot$ Stem canker

\section{Introduction}

The development of disease in cultivated crops has long been known to depend on complex interactions between pathogen, host and prevailing environmental conditions. Organisms occupying the same niche also interact with each other, and

Electronic supplementary material The online version of this article (https://doi.org/10.1007/s41348-020-00346-6) contains supplementary material, which is available to authorized users.

Maria Viketoft

maria.viketoft@slu.se

1 Department of Ecology, Swedish University of Agricultural Sciences (SLU), PO Box 7044, 75007 Uppsala, Sweden

2 Department of Biosystems and Technology, Swedish University of Agricultural Sciences (SLU), PO Box 103, 23053 Alnarp, Sweden

3 Department of Forest Mycology and Plant Pathology, Swedish University of Agricultural Sciences (SLU), PO Box 7026, 75007 Uppsala, Sweden plant pathogens are no exceptions. In many crops throughout the world, it has been demonstrated that nematodes play a significant role for the development of diseases caused by other soil-borne pathogens, and particularly prevalent are interactions between plant-parasitic nematodes and species of plant pathogenic fungi (Back et al. 2002). There are several possible mechanisms behind these interactions. For example, plant-parasitic nematodes may cause a wide range of lesions on the roots of the host plant that facilitate for fungal hyphae to infect (Francl and Wheeler 1993), or cause physiological changes in the host plant leading to increased secretion of root exudates, increased number of lateral roots and changes in the chemical composition of root exudates that may attract the fungi as well as increase the sensitivity for fungal infection (Back et al. 2002). Equally, fungal infection can cause a deterioration or decrease of the host resistance, which may lead to larger nematode populations (Taheri et al. 1994; Back et al. 2002). Therefore, when occurring together, fungi and nematodes may act independently and cause an additive effect on damage and yield or interact with 
each other in a synergistic or antagonistic way leading to more and less damage, respectively.

Stem canker and other symptoms caused by the plant pathogenic fungus Rhizoctonia solani Kühn are considered as major problems for potato growers in Sweden, especially in conventional growing systems, which often have shorter crop rotations. Rhizoctonia solani attacks all parts of the potato plants; the germinating stem (stem canker), the roots and stolons become brown and the tubers are often developed close beneath the soil surface and are often covered with sclerotia on the skin (black scurf), have cracks in the skin (elephant hide), have narrow holes in the tuber (dry core) or are deformed (Bandy et al. 1988; Banville 1989; Carling et al. 1989; Hausmann 2006; Muzhinji et al. 2014). The fungus can either be seed-borne, due to the sclerotia (black scurf), or soil-borne as the mycelium can survive on harvest residues. The soil-borne inoculum is considered to be the most detrimental, as there is the possibility to circumvent the seed-borne inoculum by treating the seed tubers with fungicides in conventional farming. The fungus is attracted to the plant through the root exudates released from the plant (Back et al. 2010) and therefore, there is potential for interaction with plant-parasitic nematodes.

The interactions between $R$. solani and the potato cyst nematodes Globodera rostochiensis (Wollenweber) Behrens (Back et al. 2006, 2010) and Globodera pallida (Stone) Behrens (Bhattarai et al. 2009, 2010) have been quite well studied. These nematodes are sedentary endoparasites that establish a permanent feeding site inside the root. It was found that juveniles of G. rostochiensis attacking potato roots were associated with higher abundance of stolons infected by $R$. solani (Back et al. 2006). The suggested explanation was that the juveniles modify the discharge of exudates during the beginning of the invasion of the root (Back et al. 2010). The disease development was also greater with G. pallida than with $G$. rostochiensis, which may be due to the longer juvenile stage for G. pallida (Robinson et al. 1987; Bhattarai et al. 2009). A long juvenile stage with low hatching rate and high survival rate due to better utilization of the fat reserves will prolong the interaction period, as for G. pallida (Robinson et al. 1987).

Interactions between $R$. solani and plant-parasitic nematodes with less specialized feeding behaviour are less well studied. In potato, studies on the interaction between $R$. solani and root-lesion nematodes, which are migratory endoparasites, have yielded contradictory results. Scholte and s'Jacob (1989) did not find any interaction between Pratylenchus neglectus (Rensch) Filipjev \& SchuurmansStekhoven and $R$. solani, while Kotcon et al. (1985) found lower tuber yield in plots infested with both $R$. solani and Pratylenchus penetrans (Cobb) Filipjev \& SchuurmansStekhoven. In addition, interactions between $P$. penetrans and other fungal pathogens have been found in several other agricultural crops. For example, strawberry plants inoculated with P. penetrans and Rhizoctonia fragariae Husain \& McKeen on the same half of a split-root strawberry crown had greater levels of black root rot than plants either inoculated with $P$. penetrans and $R$. fragariae on different halves of the root system, or inoculated with $P$. penetrans or $R$. fragariae separately (LaMondia 2003). In potato, the disease complex of Verticillium dahliae Kleb. and P. penetrans is well known and has been found to result in greater yield loss than caused by $V$. dahliae alone (Rowe et al. 1985).

The aim of the present study was to make a first step in unravelling the interactions between the plant pathogenic fungus $R$. solani and the root-lesion nematode P. penetrans, by controlling the presence and/or abundance of the pathogens in pot experiments. The hypotheses were that the combination of $R$. solani and $P$. penetrans would result in (1) more severe stem canker, (2) reduced quality of the tubers due to higher incidence of black scurf and other tuber symptoms, and (3) concomitant lower tuber yield. It was also hypothesized that adding a high level of nematodes would result in (4) more nematode damages.

\section{Materials and methods}

This study consisted of two experiments with some minor differences in the experimental setup concerning the nematode treatments. In addition, the grading of damages in experiment 1 was insufficient, indicating a need for a second experiment to be able to address the hypotheses properly. The second experiment was part of a larger experiment (Edin et al. 2019).

\section{Fungus}

An isolate of Rhizoctonia solani, anastomosis group 2 (AG21), originating from Vara, Sweden, was kindly provided by Dr. S. Ahlström at the Department of Forest Mycology and Plant Pathology, SLU, Uppsala, Sweden, which was the same isolate used in the experiments previously published (Edin and Viketoft 2017; Viketoft et al. 2017; Edin et al. 2019). The methodology was also the same as in those experiments, i.e. the fungus was grown on potato dextrose broth (PDB) dishes for a week and then the filamentous mycelium was harvested and washed with phosphate-buffered saline (PBS). The mycelium was mixed to small pieces and diluted in tap water to correspond to $0.1 \mathrm{~g}$ mycelium pot ${ }^{-1}$ within the same volume as for the inoculation of the nematodes.

\section{Nematodes}

Second stage juveniles of the root-lesion nematode, Pratylenchus penetrans, were purchased from Plant 
Research International, Wageningen, the Netherlands, and kept in culture on maize. The nematodes were extracted from the maize roots using trays (Whitehead and Hemming 1965), and kept in a cold storage room $\left(4^{\circ} \mathrm{C}\right)$ in a $3 \mathrm{~L}$ glass beaker that was aerated with an aquarium air pump (SuperFish Air-Flow mini) until inoculation. At inoculation, the concentration of nematodes in the solution was determined by counting the nematodes in five replicates of $2 \mathrm{ml}$ samples in a counting disc.

\section{Experimental setup}

The experiments were designed as pot experiments with six and four treatments, respectively (Table 1), with eight replicates. Pots $(12 \times 12 \times 25 \mathrm{~cm}$, drainage holes covered with filter paper) were filled with $1600 \mathrm{~g}$ of washed, sterilized sand $\left(0-3 \mathrm{~mm} \varnothing ; 200{ }^{\circ} \mathrm{C}\right.$ for $\left.6 \mathrm{~h}\right)$ and $200 \mathrm{ml}$ of tap water was added. One pre-germinated mini-tuber of cultivar King Edward VII (produced from meristem cultures, cultivated at The Finnish Seed Potato Centre Ltd (SPK), Tyrnävä, Finland) was placed in each pot with the most germinated sprouts facing upwards. For experiment 1 the mini-tubers were of size class $25-30 \mathrm{~mm}$ and for experiment 2 they were of size class $20-25 \mathrm{~mm}$. Another $900 \mathrm{~g}$ sand were added on top of the tuber and $100 \mathrm{ml}$ tap water was applied. In experiment 2 the inoculations were performed the day after the planting but in experiment 1 they were made 4 days after planting; the pots were covered with aluminium foil and received $200 \mathrm{ml}$ of tap water during that period. During the inoculation, the fungus, the nematodes, and water were added in different combinations to the pots: control (tap water), fungus ( $0.1 \mathrm{~g}$ fresh mycelium per pot), low level of nematodes (ca 2500 nematodes per pot), medium level of nematodes (ca 5000 nematodes per pot) and high level of nematodes (ca 7500 nematodes per pot). Both fungus and nematodes were added to the pots as a water solution spread over the soil surface with a $0.25 \mathrm{~L}$ metal cup. The actual inoculum volume differed between the experiments due to variations in nematode density, but the volumes added for each treatment were always the same within each experiment. For example, in experiment 1 the volume of $60 \mathrm{ml}$ of liquid solution contained either $15 \mathrm{ml}$ (low level) or $45 \mathrm{ml}$ (high level) of nematode solution, $15 \mathrm{ml}$ fungal solution and/ or tap water according to the treatments in Table 1.

The experiments were carried out in a climate chamber set to $12{ }^{\circ} \mathrm{C}$ with a day/night cycle of $16 / 8 \mathrm{~h}$ and artificial light (152 LUX on average). This temperature was chosen to mimic the conditions of spring in areas suitable for growing potatoes; the 30-year average temperature for May is $6-11^{\circ} \mathrm{C}$ and $12-15^{\circ} \mathrm{C}$ for June (SMHI 2017). The pots were placed on trolleys in a randomized complete block design. The trolleys were rotated once a week to provide uniform exposure to light. The pots were watered twice a week with tap water to ensure normal moisture and during the last weeks, depending on the growth level, the plants were watered thrice a week. In addition, all pots were fertilized at four occasions with a complete fertilizer (Blomstra NPK: 100:18:86 and micronutrients, Orkla Care, Solna, Sweden). In total, each plant received $290 \mathrm{mg} \mathrm{N}$ in experiment 1 and $200 \mathrm{mg} \mathrm{N}$ in experiment 2.

\section{Harvest}

The potato plants were harvested 10 or 11 weeks after inoculation (Table 1). The potato plant was taken out of the pot, washed carefully with tap water, dried with a paper towel and divided into stems, roots, stolons and tubers. The tubers were divided into small $(0.5-2 \mathrm{~cm}$ in diameter) and large ( $>2 \mathrm{~cm}$ in diameter), and tubers smaller than $0.5 \mathrm{~cm}$ were regarded as stolons. In experiment 1 , the plant parts were
Table 1 Details on inoculations and harvest in the two experiments with the pathogenic fungus Rhizoctonia solani and the root-lesion nematode Pratylenchus penetrans. For details on the grading of plant parts see Supplementary

Table S1

\begin{tabular}{llll}
\hline & & Exp. 1 & Exp. 2 \\
\hline $\begin{array}{l}\text { Inoculations } \\
\text { 1. Control (C) }\end{array}$ & & $\mathrm{X}$ & $\mathrm{X}$ \\
2. Fungus (F) & & $\mathrm{X}$ & $\mathrm{X}$ \\
3. Nematode & 3(a) Low level (NL): 1 nematode $\mathrm{g}^{-1}$ sand & $\mathrm{X}$ & \\
& 3(b) Medium level (N): 2 nematodes $\mathrm{g}^{-1}$ sand & & $\mathrm{X}$ \\
& 3(c) High level (NH): 3 nematodes $\mathrm{g}^{-1}$ sand & $\mathrm{X}$ & \\
4. Combination & 4(a) F+ NL & $\mathrm{X}$ & $\mathrm{X}$ \\
& 4(b) F+ N & & \\
& 4(c) F+ NH & $\mathrm{X}$ & 10 weeks \\
Harvest & Canker (stem, stolons) & 11 weeks & Graded \\
& Sclerotia (stem, stolons, roots, tubers) & Graded & Counted \\
& Elephant hide (tubers) & Graded & Graded \\
& Nematode lesions (stem, stolons, roots, tubers) & Graded & Counted \\
\hline
\end{tabular}


graded regarding nematode damage (number of lesions), stem canker, sclerotia and elephant hide (Supplemental Table S1). The severity of stem canker and elephant hide were graded in the same way in experiment 2 , while the actual number of sclerotia and nematode lesions were instead counted on each plant part. The mother tuber was measured in length and diameter and graded regarding nematode damage and sclerotia (black scurf).

The submerged part of the main stem (from the mother tuber up to the surface level, $5-8 \mathrm{~cm}$ ), the largest tuber, ten roots and 20-25 g of the potting medium were weighed separately and put in plastic bags for cold storage $\left(4^{\circ} \mathrm{C}\right)$ for later extraction of nematodes. The remaining plant parts were weighed and dried for dry weight measurements $\left(75^{\circ} \mathrm{C}\right.$ for $48 \mathrm{~h}$ ) and $100 \mathrm{~g}$ of the potting medium were weighed and dried $\left(105{ }^{\circ} \mathrm{C}\right.$ for $\left.24 \mathrm{~h}\right)$ for determination of water content.

\section{Nematode extraction}

For nematode extraction, the plant material and potting medium were placed in mesh net sieves covered with vlieseline filters. The main stem part and roots were cut into $1 \mathrm{~cm}$ pieces and the tubers were divided into four pieces and placed skin side down. The sieves were placed in Baermann funnels, and the nematodes were extracted for $24 \mathrm{~h}$, heatkilled and fixated in formalin (Viketoft et al. 2005). As the focus of the study is the difference among the treatments, we believe that an extraction time of $24 \mathrm{~h}$ from the plant parts give valuable information although we will not recover all nematodes. The number of nematodes was estimated in the suspensions from each extraction under low magnification (50x) and expressed as number of nematodes per gram dry weight of each plant part or per gram dry potting sand.

\section{Statistical analyses}

In experiment 1 , the effects of additions of fungus and nematodes on dry weight of stems, tubers, roots and stolons as well as the number of nematodes in the different plant parts and in the potting medium were analysed with randomized complete block design ANOVA followed by Tukey adjusted multiple comparisons using R version 3.1.1 (R Core Team 2013). To account for heteroscedasticity, heteroscedastic consistent covariance estimation, packages multcomp (Hothorn et al. 2008) and sandwich (Zeileis 2004, 2006), was used. The number of tubers and stems were analysed with Poisson regression using $\mathrm{R}$, with the control treatment used as baseline, followed by Tukey adjusted multiple comparisons to investigate differences in numbers among the treatments. The proportion of small tubers were analysed with binomial regression using SAS for Windows 9.3 (SAS Institute Inc., Cary, NC, USA). To analyse the effect on fungal and nematode damage we used a dichotomous variable - damage (some gradings per plant $>0$ ) or no damage (all gradings per plant 0 ). In addition, due to too few observations (Agresti 2013), only damage on stems and tubers could be analysed. The data was analysed with binomial regression using $\mathrm{R}$.

For experiment 2, randomized complete block design ANOVA (estimated using R version 3.5.2 (R Core Team 2018) and the lme4 package (Bates et al. 2015) with block as random factor, was applied to stem, root and stolon biomass, number of stems and tubers, proportion of small tubers, severity of sclerotia, stem canker and nematode damage on stem, and abundance of plant-feeding nematodes in growing medium, tubers, stem and roots. The log-transform was used for number of tubers and the log-plus-one transform was used for severity of stem canker and nematode damage on stem, due to better results in tests for normality and equal variance for the residuals (diagnostics test performed using the car package (Fox and Weisberg 2011)). Significance of added nematodes, added fungus and the interaction of nematodes and fungus was tested using Type II Wald Chi-square tests and post hoc comparisons between factor levels were done by the Tukey adjusted multiple comparisons, using the emmeans package (Lenth 2018). All statistical tests were performed with a significance level of $5 \%(p \leq 0.05)$.

\section{Results}

There was no obvious difference in emergence time between the different treatments, and all potato plants developed well. The potato plants in pots inoculated with $R$. solani were infected by stem canker and black scurf. The nematode $P$. penetrans were present in all plant parts and potting medium samples where nematodes had been added. Bacteriophagous nematodes were also present, especially in the potting medium samples, but were not considered important for the experiment.

\section{Impact on stems}

At harvest, the dry weight of stems differed among the treatments in experiment 1 . The treatment with $R$. solani and high level of nematodes had more aboveground biomass than the control $(p=0.002)$ and the two nematode treatments $(p<0.001$ and $p=0.002)$ (Table 2). In addition, the dry weight of stems was also greater for the fungal treatment compared to the two nematode treatments $(p<0.001$ and $p=0.002)$. The treatment with $R$. solani and low level of nematodes did not differ in dry weight from the other treatments, but these plants had more stems compared to the fungus treatment $(p=0.005)$ and low nematode treatment $(p=0.002)$ (Table 2). In 
Table 2 Dry weights [g; mean (SE)] and numbers of different parts of potato plants subjected to different combinations of the plant pathogenic fungus Rhizoctonia solani and the root-lesion nematode Pratylenchus penetrans $(n=8)$

\begin{tabular}{lllllll}
\hline Treatment & No. of stems & Stem biomass & Stolon biomass & Root biomass & No. of tubers & Proportion small tubers $^{\mathrm{a}}$ \\
\hline Experiment 1 & & & & & & \\
Control (C) & $3.3(0.3) \mathrm{ab}$ & $5.85(0.22) \mathrm{bc}$ & $0.26(0.03) \mathrm{a}$ & $1.08(0.08)$ & $8.8(1.1) \mathrm{ab}$ & $0.41(0.08) \mathrm{b}$ \\
Fungus (F) & $2.3(0.4) \mathrm{b}$ & $7.46(0.40) \mathrm{ab}$ & $0.04(0.01) \mathrm{b}$ & $1.13(0.08)$ & $8.3(1.2) \mathrm{ab}$ & $0.52(0.05) \mathrm{ab}$ \\
Nematodes low level (NL) & $2.0(0.3) \mathrm{b}$ & $5.49(0.15) \mathrm{c}$ & $0.29(0.04) \mathrm{a}$ & $0.98(0.06)$ & $10.0(0.9) \mathrm{ab}$ & $0.51(0.05) \mathrm{ab}$ \\
Nematodes high level (NH) & $3.6(0.8) \mathrm{ab}$ & $5.71(0.24) \mathrm{c}$ & $0.22(0.02) \mathrm{a}$ & $1.04(0.04)$ & $11.8(1.6) \mathrm{a}$ & $0.56(0.05) \mathrm{ab}$ \\
$\mathrm{F}+\mathrm{NL}$ & $6.0(1.3) \mathrm{a}$ & $6.55(0.77) \mathrm{abc}$ & $0.12(0.03) \mathrm{b}$ & $0.95(0.08)$ & $8.6(1.8) \mathrm{ab}$ & $0.75(0.07) \mathrm{a}$ \\
$\mathrm{F}+\mathrm{NH}$ & $4.6(0.9) \mathrm{ab}$ & $8.34(0.72) \mathrm{a}$ & $0.05(0.01) \mathrm{b}$ & $1.23(0.10)$ & $6.6(1.1) \mathrm{b}$ & $0.56(0.06) \mathrm{ab}$ \\
Experiment 2 & & & & & \\
$\mathrm{C}$ & $1.6(0.2)$ & $4.52(0.3)$ & $0.21(0.03) \mathrm{a}$ & $0.84(0.09) \mathrm{a}$ & $6.50(0.6) \mathrm{ab}$ & $0.37(0.04) \mathrm{a}$ \\
$\mathrm{F}$ & $1.5(0.3)$ & $3.95(0.2)$ & $0.09(0.02) \mathrm{b}$ & $0.78(0.08) \mathrm{ab}$ & $4.63(0.6) \mathrm{b}$ & $0.32(0.08) \mathrm{a}$ \\
$\mathrm{N}$ & $2.1(0.3)$ & $4.00(0.2)$ & $0.16(0.03) \mathrm{ab}$ & $0.65(0.06) \mathrm{ab}$ & $7.25(1.1) \mathrm{ab}$ & $0.50(0.05) \mathrm{a}$ \\
$\mathrm{F}+\mathrm{N}$ & $2.0(0.3)$ & $4.13(0.4)$ & $0.10(0.03) \mathrm{b}$ & $0.57(0.05) \mathrm{b}$ & $8.50(1.4) \mathrm{a}$ & $0.47(0.08) \mathrm{a}$ \\
\hline
\end{tabular}

${ }^{a}$ In experiment 2, the ANOVA test shows a significant effect of added nematodes, but the Tukey test does not show any significant separation when all four treatment levels are used

Treatments with the same letter within a column and experiment are not significantly different at level $p \leq 0.05$

experiment 2, presence of $R$. solani or nematodes did not significantly affect either dry weight of stems or number of stems (Table 2).

There was no effect of treatment on either fungal damage (stem canker, sclerotia) or nematode damage on the stems in any of the experiments (Table 3). There was a significant effect of treatment on the number of nematodes in stems in experiment $1(p=0.02)$, but not in experiment 2. However, the multiple comparisons could not distinguish among the treatments, but the presence of the fungus seemed to increase the number of nematodes when the level was high (Table 4).

\section{Impact on stolons}

In both experiments, the dry weights of stolons were reduced in all treatments containing $R$. solani $(p<0.001)$ (Table 2$)$. The stolons were both few and very short due to the fungus.

\section{Impact on tubers}

In experiment 1 , neither the addition of fungus nor nematodes had an effect on the number of tubers compared to the control, but when high level of nematodes were present, the combination with $R$. solani resulted in fewer tubers than if the nematodes occurred alone $(p=0.011)$ (Table 2). In experiment 2 , inoculation of nematodes
Table 3 Percentage of stems and tubers with fungal and nematode damages from potato plants subjected to different combinations of the plant pathogenic fungus Rhizoctonia solani (F) and the root-lesion nematode Pratylenchus penetrans $(\mathrm{N})$ - low $(\mathrm{L})$ and high level (L) in experiment 1

\begin{tabular}{|c|c|c|c|c|c|c|c|}
\hline \multirow[t]{2}{*}{ Treatment } & \multicolumn{4}{|c|}{ Stems } & \multicolumn{3}{|l|}{ Tubers } \\
\hline & \multicolumn{2}{|c|}{$\begin{array}{l}\text { Stem } \\
\text { canker }^{\mathrm{a}}\end{array}$} & Sclerotia & $\begin{array}{l}\text { Nematode } \\
\text { lesions }\end{array}$ & Black scurf & Elephant hide & $\begin{array}{l}\text { Nema- } \\
\text { tode } \\
\text { lesions }\end{array}$ \\
\hline \multicolumn{8}{|l|}{ Experiment 1} \\
\hline Fungus (F) & \multicolumn{2}{|l|}{100} & 50 & - & 39 & 59 a & - \\
\hline Nematodes low level (NL) & \multicolumn{2}{|l|}{-} & - & 100 & - & - & 11 \\
\hline Nematodes high level (NH) & \multicolumn{2}{|l|}{-} & - & 100 & - & - & 43 \\
\hline $\mathrm{F}+\mathrm{NL}$ & \multicolumn{2}{|l|}{83} & 27 & 77 & 20 & $22 \mathrm{~b}$ & 26 \\
\hline $\mathrm{F}+\mathrm{NH}$ & \multicolumn{2}{|l|}{84} & 24 & 65 & 25 & $32 \mathrm{~b}$ & 53 \\
\hline \multicolumn{8}{|l|}{ Experiment 2} \\
\hline $\mathrm{F}$ & 77 & 77 & 77 & - & 54 & 51 & - \\
\hline $\mathrm{N}$ & - & - & - & 100 & - & - & 33 \\
\hline $\mathrm{F}+\mathrm{N}$ & 75 & 81 & 88 & 94 & 37 & 62 & 41 \\
\hline
\end{tabular}

${ }^{\text {a }}$ Separated into severity grade 1 and severity grade $2-3$ for experiment 2 
Table 4 Abundances of the root-lesion nematode Pratylenchus penetrans (no. $\mathrm{g}^{-1}$ dry weight; mean (SE)) in different parts of potato plants subjected to the plant pathogenic fungus Rhizoctonia solani $(\mathrm{F})$ and nematodes $(\mathrm{N})$ low $(\mathrm{L})$ and high $(\mathrm{H})$ level in experiment 1

\begin{tabular}{lllrl}
\hline Treatment & Stems & Tubers & Roots & Potting medium \\
\hline Experiment 1 & & & & \\
Nematodes low level (NL) & $196(41)$ & $0.7(0.6) \mathrm{b}$ & $1569(497)$ & $0.55(0.21) \mathrm{b}$ \\
Nematodes high level (NH) & $389(98)$ & $0.7(0.2) \mathrm{b}$ & $1591(402)$ & $0.93(0.28) \mathrm{ab}$ \\
Fungus (F) + NL & $177(69)$ & $3.8(2.1) \mathrm{ab}$ & $950(404)$ & $0.55(0.21) \mathrm{b}$ \\
$\mathrm{F}+\mathrm{NH}$ & $686(384)$ & $5.1(2.3) \mathrm{a}$ & $1200(324)$ & $2.01(0.82) \mathrm{a}$ \\
Experiment 2 & & & & \\
$\mathrm{N}$ & $122(35)$ & $1.6(0.7)$ & $743(113)$ & $0.25(0.12)$ \\
$\mathrm{F}+\mathrm{N}$ & $130(36)$ & $3.9(1.1)$ & $1391(425)$ & $0.13(0.04)$ \\
\hline
\end{tabular}

Treatments with the same letter within a column and experiment are not significantly different at level $p \leq 0.05$ increased the number of tubers $(p=0.026)$. In addition, in experiment 1 the combination of low level of nematodes and fungus resulted in a greater proportion of small tubers compared to the control $(p=0.003)$, while in experiment 2 addition of nematodes in general increased the proportion of small tubers $(p=0.026)$, although the multiple comparisons could not distinguish among the treatments (Table 2).

In experiment 1 , the dry weight of tubers differed among the treatments $(p<0.001)$. Plants in all treatments containing the fungus had reduced dry weight of tubers compared to the control and the two nematode treatments (Fig. 1a). In experiment 2, there was an individual effect of both fungus and nematodes, both leading to lower dry weight of tubers, but no interaction effect (Fig. 1b).

Damages of both nematodes and fungus, respectively, were found on the tubers in the pots where they had been inoculated in both experiments. For fungal damage in the form of elephant hide, the likelihood was lower when the fungus was added in combination with nematodes in experiment 1 , both at low $(p<0.001)$ and high level $(p=0.009)$. This is indicated by the lower percentage of tubers with elephant hide in the combined treatments (Table 3). However, this was not found in experiment 2 where nematodes did not affect the likelihood of elephant hide. The occurrence of black scurf on the tubers was not affected by the presence of nematodes in either of the experiments (Table 3 ).

For occurrence of visible nematode damages, addition of the higher level of nematodes in experiment 1 resulted in higher probability than the low level $(p<0.001)$ (Table 3), but presence of the fungus had no effect on the probability of nematode damages in either of the experiments. In addition, the number of nematodes in the tubers was affected by treatment in experiment $1(p=0.02)$, where the combination of $R$. solani and high level of nematodes increased the prevalence of nematodes in tubers compared to addition of the nematodes alone (Table 4).
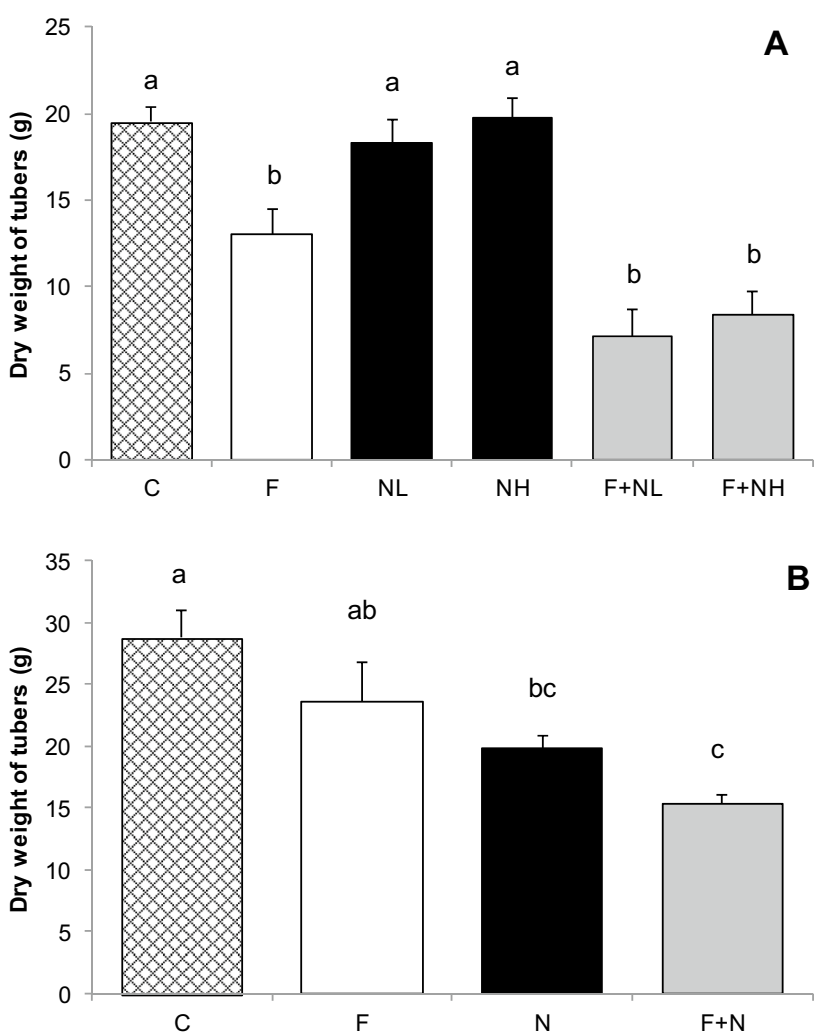

Fig. 1 Dry weight of tubers [g; mean (SE)] of potato plants subjected to different combinations of the plant pathogenic fungus Rhizoctonia solani $(\mathrm{F})$ and the root-lesion nematode Pratylenchus penetrans $(\mathrm{N})$. In experiment 1 (a) there were two levels of nematode addition, low $(\mathrm{NL})$ and high $(\mathrm{NH})$, while in experiment 2 (b) there was only one (intermediate). Treatments with the same letter above the bar are not significantly different at level $p \leq 0.05$

\section{Impact on roots}

Addition of fungus and nematodes did not significantly affect the dry weight of roots in experiment 1 , but in experiment 2 inoculation of nematodes reduced the root biomass (Table 2). The roots had brown lesions or sections regardless of treatment and were always covered with sclerotia if $R$. 
solani had been added. There was no significant difference among the treatments in the number of nematodes in roots in both experiments (Table 4).

\section{Potting medium}

There was a significant effect of treatment on the number of nematodes in the potting medium in experiment $1(p=0.02)$, but not in experiment 2 . In experiment 1 , more nematodes were found in the potting sand with addition of fungus and high level of nematodes compared to low nematodes only $(p=0.01)$, and fungus and low nematodes $(p=0.01)$ (Table 4).

\section{Discussion}

Contrary to our first hypothesis, we found no effect of presence of nematodes on the incidence of stem canker. The second hypothesis was not supported either as we found no effect of nematodes on the severity of black scurf, and the likelihood for elephant hide was even reduced in presence of nematodes in one of the experiments. Also, the hypothesis about lower tuber yield when both pathogens occurred together was rejected, as the decrease in yield did not exceed the sum of the individual effects of the two organisms. As hypothesized, a high level of nematodes resulted in more visible nematode damages, but beyond that the different nematode levels rendered in most cases similar responses. Interestingly, there was no effect of presence of $R$. solani on visible nematode damages, but the fungus increased the number of nematodes in the tubers.

All the plants emerged well in both experiments, so the conditions seemed to have been optimal for growth of the potato plants enabling them to emerge before being heavily attacked by the fungus. However, there are differences in plant growth between the experiments, with more stem biomass and stems in experiment 1 , possibly related to the larger size of the seed tubers in combination with longer growth period and greater total $N$ addition. It is usually the seed infection of $R$. solani that reduces the emergence and not the soil-borne inoculum (Carling et al. 1989). Therefore, it was not surprising that there were no large differences among the treatments in stem dry weight at harvest either. The number of stems has previously been found to be affected by both $R$. solani and potato cyst nematodes (PCN) (Kiani et al. 2013), but the effect was cultivar specific. However, it is interesting that in the present study it is only the combination of $R$. solani and low level of nematodes that had more stems.

Previous studies have shown an effect of PCN on the incidence and damage severity of stem canker (Bhattarai et al. 2009; Kiani et al. 2013). Pratylenchus penetrans used in the present study is less specialized and does not modify the metabolism of the plants as PCN do (Hussey and Grundler 1998). Instead, P. penetrans is not only restricted to attack the roots, and therefore a more direct interaction between $R$. solani and P. penetrans could be expected than between $R$. solani and PCN. However, we could not find any effect of the nematode on the incidence and damage severity of stem canker, which could be a result of the fact that $P$. penetrans prefer the roots over the stem (Table 3). It is even possible that the nematodes first attack the roots, and then later attack the stem when the fungus is already present there (Nordmeyer and Sikora 1983). The fact that we could not detect any effect of nematodes on the incidence and severity of stem canker could also be related to the statistical method. As severity of stem canker is a graded measure, the normality assumption of the ANOVA is not met and the use of binomial regression on the dichotomized variable may have resulted in lower statistical power. However, it is difficult to compare the actual amount of $R$. solani inoculated in those studies with the amount inoculated in the present study, as the inoculation methods differed. It is possible that the inoculum level used in the present study was higher leading to severe stem canker even in the absence of nematodes. With a lower fungal inoculum level, it is likely that wounding by the nematodes is of greater importance.

The most pronounced effect of $R$. solani was found on the tubers. Potatoes infected with stem canker (R. solani) do not necessarily suffer an overall yield loss but instead a reduction in the number of marketable tubers (Weinhold et al. 1982). However, we did find a yield loss even in the presence of the fungus alone in one of the experiments. That may depend on the amount of added fungal inoculum being greater than the levels usually present in agricultural fields (Budge et al. 2009). Interestingly, the presence of nematode reduced the likelihood of elephant hide on the tubers in experiment 1. It was also noted that black scurf and elephant hide only rarely occurred together on a tuber, which also have been observed by others (J. Woodhall, FERA, personal communication). However, the reasons for that are still unknown. It is suggested that elephant hide origins from a stolon lesion caused by $R$. solani on a pre-tuber which then grows out to form a tuber (J. Woodhall, FERA, personal communication), while black scurf is formed from mycelia growing on the tuber itself (Dijst 1988). These symptoms are therefore likely to be differently affected by nematodes, but the mechanisms behind the reduction in incidence of elephant hide are difficult to discern from this study.

The root-lesion nematode $P$. penetrans may alone cause considerable yield loss, by $30-70 \%$, in the potato crop (e.g. Bernard and Laughlin 1976; Holgado et al. 2009; Morgan et al. 2002; Olthof 1989; Philis 1995). However, in the present study a lower tuber yield due to nematodes compared to the control was only found in experiment 2 (Fig. 1). 
The economic threshold of $P$. penetrans on potato crops is reported to be of 100-250 specimens per $250 \mathrm{~g}$ soil (Brodie et al. 1993; Holgado et al. 2009), and this would infer that even our low level ( 1 nematode $\mathrm{g}^{-1}$ potting sand) could potentially be economically damaging. In experiment 2 , the nematodes were retrieved from locally kept maize cultures and added to the pots as soon as there was enough inoculum, while for experiment 1 the nematodes were retrieved from the maize roots in the Netherlands and then transported to us. Therefore, due to the extended extraction and transportation the nematodes were kept around 1 week in water before being added to the pots in experiment 1 and their vigour may have been reduced at inoculation. In addition, the seed tubers just barely had sprouts at inoculation, which means there was also a limited food supply for the nematodes at first. The fact that the potato plants were harvested prematurely in these pot experiments could also account for some of the difference to estimated yield losses due to $P$. penetrans in the field.

The amount of visible nematode damages on the tubers was consistently related to the number of inoculated nematodes across the experiments, as the percentage of tubers with nematode damage in experiment 2 nicely fits in between the percentages found in experiment 1 . However, the number of nematodes in the different plant parts increased with the higher level of nematodes but not corresponding to the difference in inoculum level. This suggests that the carrying capacity had been reached and the nematodes were constrained by competition. The greater amount of nematodes in the potting sand in the high level nematode treatment, especially in combination with $R$. solani, also points towards the fact that the nematodes were looking for new fresh roots to attack.

\section{Conclusion}

We have shown that there seems to be an additive effect of the plant pathogenic fungus $R$. solani and the root-lesion nematode $P$. penetrans on yield loss in potato. In addition, the nematode levels in this experiment did not affect the incidence of stem canker and in some cases the nematodes could even reduce tuber symptoms in form of elephant hide. Our results suggest that the fungus and nematodes affect each other in different ways in the different parts of the potato plant, but the exact mechanisms still need to be elucidated. Knowledge about interactions between pathogens, as the one showed here, is essential for choosing appropriate management methods for disease control.

Acknowledgements Open access funding provided by Swedish University of Agricultural Sciences. We thank personnel and students at the Department of Ecology, SLU, for help during the harvest of the experiments. This research was funded by The Swedish Farmers' Foundation for Agricultural Research (grant number H1142045).

Author contributions Conception, design, material preparation and data collection were performed by Maria Viketoft and Eva Edin. Analyses were performed by Adam Flöhr, Jan-Eric Englund and Jonas Kardell. The first draft of the manuscript was written by Maria Viketoft and all authors commented on previous versions of the manuscript. All authors read and approved the final manuscript.

\section{Compliance with ethical standards}

Conflict of interest The authors declare that they have no conflict of interest.

Open Access This article is licensed under a Creative Commons Attribution 4.0 International License, which permits use, sharing, adaptation, distribution and reproduction in any medium or format, as long as you give appropriate credit to the original author(s) and the source, provide a link to the Creative Commons licence, and indicate if changes were made. The images or other third party material in this article are included in the article's Creative Commons licence, unless indicated otherwise in a credit line to the material. If material is not included in the article's Creative Commons licence and your intended use is not permitted by statutory regulation or exceeds the permitted use, you will need to obtain permission directly from the copyright holder. To view a copy of this licence, visit http://creativecommons.org/licenses/by/4.0/.

\section{References}

Agresti A (2013) Categorical data analysis. Wiley, Hoboken

Back MA, Haydock PPJ, Jenkinson P (2002) Disease complexes involving plant parasitic nematodes and soilborne pathogens. Plant Pathol 51:683-697

Back M, Haydock P, Jenkinson P (2006) Interactions between the potato cyst nematode Globodera rostochiensis and diseases caused by Rhizoctonia solani AG3 in potatoes under field conditions. Eur J Plant Pathol 114:215-223

Back M, Jenkinson P, Deliopoulos T, Haydock P (2010) Modifications in the potato rhizosphere during infestations of Globodera rostochiensis and subsequent effects on the growth of Rhizoctonia solani. Eur J Plant Pathol 128:459-471

Bandy BP, Leach SS, Tavantzis SM (1988) Anastomosis group-3 is the major cause of rhizoctonia disease of potato in Maine. Plant Dis 72:596-598

Banville GJ (1989) Yield losses and damage to potato plants caused by Rhizoctonia solani Kühn. Amer Potato J 66:821-834

Bates D, Mächler M, Bolker B, Walker S (2015) Fitting linear mixedeffects models using lme4. J Stat Softw 67:1-48

Bernard EC, Laughlin CW (1976) Relative susceptibility of selected cultivars of potato to Pratylenchus penetrans. J Nematol $8: 239-242$

Bhattarai S, Haydock PPJ, Back MA, Hare MC, Lankford WT (2009) Interactions between the potato cyst nematodes, Globodera pallida, G. rostochiensis, and soil-borne fungus, Rhizoctonia solani (AG3), diseases of potatoes in the glasshouse and the field. Nematology 11:631-640

Bhattarai S, Haydock PPJ, Back MA, Hare MC, Lankford WT (2010) Interactions between field populations of the potato cyst nematode Globodera pallida and Rhizoctonia solani diseases of potatoes 
under controlled environment and glasshouse conditions. Nematology 12:783-790

Brodie BB, Evans K, Franco J (1993) Nematode parasites of potatoes. In: Evans K, Trudgill DL, Webster JM (eds) Plant parasitic nematodes in temperate agriculture. CABI, Wallingford, pp 87-132

Budge GE, Shaw MW, Colyer A, Pietravalle S, Boonham N (2009) Molecular tools to investigate Rhizoctonia solani distribution in soil. Plant Pathol 58:1071-1080

Carling DE, Leiner RH, Westphale PC (1989) Symptoms, signs and yield reduction associated with rhizoctonia disease of potato induced by tuber-borne inoculum of Rhizoctonia solani AG-3. Amer Potato J 66:693-701

Dijst G (1988) Formation of sclerotia by Rhizoctonia solani on artificial media and potato tubers. Neth J Plant Pathol 94:233-242

Edin E, Viketoft M (2017) Free-living plant-parasitic nematodes do not affect the efficiency of seed tuber fungicide treatment against Rhizoctonia solani. Amer J Potato Res 94:258-265

Edin E, Gulsher M, Andersson Franko M, Englund J-E, Flöhr A, Kardell J, Viketoft M (2019) Temporal Interactions between root-lesion nematodes and the fungus Rhizoctonia solani lead to reduced potato yield. Agronomy 9:361. https://doi.org/10.3390/ agronomy 9070361

Fox J, Weisberg S (2011) An R companion to applied regression. Sage, Thousand Oaks

Francl LJ, Wheeler TA (1993) Interaction of plant-parasitic nematodes with wilt-inducing fungi. In: Khan MW (ed) Nematode interactions. Chapman \& Hall, London, pp 79-103

Hausmann R (2006) Untersuchungen zu Rhizoctonia solani (Dry Core). Kartoffelbau, pp 318-321

Holgado R, Oppen Skau KA, Magnusson C (2009) Field damage in potato by lesion nematode Pratylenchus penetrans, its association with tuber symptoms and its survival in storage. Nematol Medit 37:25-29

Hothorn T, Bretz F, Westfall P (2008) Simultaneous inference in general parametric models. Biom J 50:346-363

Hussey RS, Grundler FMW (1998) Nematode parasitism of plants. In: Perry RN, Wright DJ (eds) The physiology and biochemistry of free-living and plant-parasitic nematodes. CABI, Wallingford, pp 213-243

Kiani Z, Zafari D, Rezaee S, Arjmandian A, Gitti M, Struik PC (2013) Co-limitation of potato growth by potato cyst nematode (Globodera rostochiensis) and Rhizoctonia solani. Arch Phytopathol Plant Prot 46:2401-2408

Kotcon JB, Rouse DI, Mitchell JE (1985) Interactions of Verticillium dahliae, Colletotrichum coccodes, Rhizoctonia solani, and Pratylenchus penetrans in the early dying syndrome of Russet Burbank potatoes. Phytopathol 75:68-74

LaMondia JA (2003) Interaction of Pratylenchus penetrans and Rhizoctonia fragariae in strawberry black root rot. J Nematol 35:17-22

Lenth R (2018) emmeans: estimated marginal means, aka least-squares means. https://rdrr.io/cran/emmeans/

Morgan GD, MacGuidwin AE, Zhu J, Binning LK (2002) Population dynamics and distribution of root lesion nematode (Pratylenchus penetrans) over a three-year potato crop rotation. Agron J 94:1146-1155

Muzhinji N, Woodhall JW, Truter M, van der Waals JE (2014) Elephant hide and growth cracking on potato tubers caused by Rhizoctonia solani AG3-PT in South Africa. Plant Dis 98:570
Nordmeyer D, Sikora RA (1983) Studies on the interaction between Heterodera daverti, Fusarium avenaceum and $F$. oxysporum on Trifolium subterraneum. Rev Nematol 6:193-198

Olthof THA (1989) Effects of fumigant and non-fumigant nematicides on Pratylenchus penetrans and yield of potato. J Nematol 21:645-649

Philis J (1995) Presence and control of Pratylenchus penetrans on potato in Cyprus. Nematol Medit 23:235-238

Robinson MP, Atkinson HJ, Perry RN (1987) The influence of soil moisture and storage time on the motility, infectivity and lipid utilization of second stage juveniles of the potato cyst nematodes Globodera rostochiensis and G. pallida. Rev Nematol 10:343-348

Rowe RC, Riedel RM, Martin MJ (1985) Synergistic interactions between Verticillium dahliae and Pratylenchus penetrans in potato early dying disease. Phytopathol 75:412-418

Scholte K, s'Jacob JJ (1989) Synergistic interactions between Rhizoctonia solani Kühn, Verticillium dahliae Kleb., Meloidogyne spp. and Pratylenchus neglectus (Rensch) Chitwood \& Oteifa, in potato. Potato Res 32:387-395

SMHI (2017) Normal medeltemperatur för maj och juni. https://www. smhi.se/data/meteorologi/temperatur/

Taheri A, Hollamby GJ, Vanstone VA, Neate SM (1994) Interaction between root lesion nematode, Pratylenchus neglectus (Rensch 1924) Chitwood and Oteifa 1952, and root rotting fungi of wheat. NZ J Crop Hort Sci 22:181-185

R Core Team (2013) R: a language and environment for statistical computing. R Foundation for Statistical Computing. http://www.Rproject.org/

R Core Team (2018) R: a language and environment for statistical computing. R Foundation for Statistical Computing. http://www.Rproject.org/

Viketoft M, Palmborg C, Sohlenius B, Huss-Danell K, Bengtsson J (2005) Plant species effects on soil nematode communities in experimental grasslands. Appl Soil Ecol 30:90-103

Viketoft M, Andersson A, Edin E (2017) Cultivar effects on the interaction between free-living plant-parasitic nematodes and the fungal pathogen Rhizoctonia solani in potato. Am J Potato Res 94:314-322

Weinhold AR, Bowman T, Hall DH (1982) Rhizoctonia disease of potato: effect on yield and control by seed tuber treatment. Plant Dis 66:815-818

Whitehead AG, Hemming JR (1965) A comparison of some quantitative methods of extracting small vermiform nematodes from soil. Ann Appl Biol 55:25-38

Zeileis A (2004) Econometric computing with HC and HAC covariance matrix estimators. J Stat Softw 11:1-17

Zeileis A (2006) Object-oriented computation of sandwich estimators. J Stat Software 16:1-16

Publisher's Note Springer Nature remains neutral with regard to jurisdictional claims in published maps and institutional affiliations. 